\title{
Study on Perception of Organization Justice among Staff of Private Sectors in Shuwaikh area of Kuwait
}

\author{
Amir Eilbeigi
}

\begin{abstract}
High turnover intention rate would negatively affect organizations' productivity and overall performance, also hiring and training new employees might result in extra expenses. Therefore, the authors of this study focused on Organizational Justice as one of the main reasons for turnover intention from the three dimensions.

Based on the following adopted variables: Interpersonal justice, Distribution justice, and procedural justice; a Distinctive study conducted by distributing the questionnaire among 273 members of private organizations to investigate and obtain appropriate answers for the given research questions of this probe.

The discoveries of theories testing exhibit that Organizational Justice significantly affects workers of private associations' turnover intention rate and outlines the solid connection between variables. The result of ebb and flow examine demonstrates that private associations in Kuwait require prompt satisfactory activity toward improving authoritative equity to create efficiency and execution of their workers toward decreasing turnover intention rates.
\end{abstract}

Index Terms - Turnover Intention, Organizational justice, Procedural, justice, Informational justice, Distributive justice, Interpersonal justice.

\section{INTRODUCTION}

\section{Problem statement}

Several researchers had stated that in non-western nations like Kuwait, the study of OJ is not taking seriously and they also claimed that the models applied in the western culture may not have the same achievement in the other cultures. While a study by Yilmaz A. and Sabahat C. (2017) argues that organizational support positively affects employees' job also significantly impacts their turnover intention. Therefore, the outcome of the research for a specific culture, shall not share the same fate for the other cultures.

As per this wonder, this examination is to propose to acquire information on the impact of OJ works in Kuwait Private Organizations and organizations, particularly from the non-scholarly laborers' point of view that is right now utilized at the association

In conclusion, the equity understood by an individual can be categorized into the following three groups:

\subsection{Distributive Justice}

Alluded to (Benjamin Schneider et al., 2017) grouping implies the advantage or preferred position of an individual

Amir Eilbeigi, Department of Project Management, Postgraduate Studies Centre, Limkokwing University of Creative Technology, Malaysia expanded considering his/her obligation toward the endeavor done by him/her in the affiliation. The other truth is underscored by (McDonough and Shakespeare, 2015) is that; the understanding of significant worth relies upon an individual's achievements being differentiated and someone else's achievements that had a comparative commitment in a comparable establishment. These achievements can be in different structures that consolidate, month to month pay rates, steady signals, prizes, respect, acknowledgment, status, joins, settled issues, and expanding other social and money related resources like an interconnected course of action of partners, time, and so forth.

\subsubsection{Procedural Justice}

Another reality that (B Schneider et al., 2017) imparted was the methodology and theory used to coordinate the consequence of an agent's dedication is portrayed by this class. As a proposal to (Tournai et al., 2016), Procedural Justice (PJ) is particularly watching the worth and sensibility of customary essential initiative plans shrunk by a foundation to measure the result an agent's dedication. The scale, on which the delegates' fulfillment and accomplishments are evaluated, should be the equivalent for all of the laborers who have comparable assignments and the assessing of these accomplishments should be significantly immediate and clear.

\subsubsection{Interpersonal Justice}

During the early decade was generally called the Interpersonal (Interactional) Justice. This characterization is progressively about how chief or an expert methodology the delegates in affiliation, and whether these laborers are being treated with balance and regard (Alkoç and Kavurmaci, 2016).

In like way, Interpersonal Justice has been delineated as reasonable lead towards a delegate by various pros in a foundation by (Whisenant, Lee, and Dees,2015a). Meanwhile, (Whisenant, Lee, and Dees, 2015b) did moreover consider and indicated that individual results including supervisory relationships have compared to Interpersonal Justice.

Alluded to (Whisenant, Lee, Dees,2015a) also recommended that help in Organizational Justice (OJ) will now and again help the affirmation of Interpersonal Justice inside an affiliation. Social Justice is organized into 4 bundles that join judgment, misleading, the encroachment of insurance, and the absence of regard (Powell, 2014).

As mentioned to accurate investigations (otherwise called empirical studies) positive Organizational Justice (OJ) would have points of interest for a foundation alongside various valuable institutional outcomes. One of these advantages is 
elevating employee TI (Georgalis, Samaratunge, Kimberly and Lu 2015; Hassan 2010). Expanded pleasure in a vocation prompts a worker being more profitable and raises the result nature of their given undertakings which in the long run will profit the establishment. For instance, expanded TI can result in a lifted aggressive edge in the organization because of the nearness of more dedicated, qualified and proficient representatives. What's more, a raised TI results in diminished Turnover Rate which in the long run will help the organization in decreasing human advancement costs (Akgunduz and Bardakoglu, 2017).

Everything considered the chief issue is to research and improve the investigations on whether Organizational Justice (OJ) has a positive or negative effect on private delegates' TI in tertiary endeavors, especially in Kuwait. Consequently, different frameworks will be executed to examine the issue. The underlying advance consolidates, totally getting a handle on and seeing an agent's understanding of significant worth down to the three characterizations said as of now which fuse, Distributive Justice, Procedural Justice, and Interpersonal Justice. Later, by finding together solutions and responses from respondents by methods for poll and reviews, the association between these 3 independent components and the reliant variable, Turnover Intention will stall.

\subsection{Research Objectives:}

The general objectives of this research are to discover workers' understanding of TI is affected by the dimensions of organizational justice.

The general point of this investigation is to discover the following terms:

1) To discover whether a worker's understanding of TI is decidedly affected by Distributive Justice.

2) To discover whether a representative's understanding of TI is decidedly affected by Procedural Justice.

3) To discover whether a representative's understanding of TI is decidedly affected by Interpersonal Justice.

\subsection{Research Questions:}

The following of the research questions for this study:

1) To what extent employee Turnover Intention in private companies in Kuwait related to Distributive Justice?

2) To what extent employee Turnover Intention in private companies in Kuwait related to Procedural Justice?

3) To what extent employee Turnover Intention in private companies in Kuwait related to Interpersonal Justice?

\section{LITERATURE REVIEW}

Organizational justice is the appraisal of an association's treatment of its workers when the sociology phrasing "Organizational Justice" was the first begat by Greenberg in 1990 (Hamlett 2014; Zhang 2006). Every one of the words utilized in the term has their different implications which will make it simpler for individuals or representatives to comprehend the phrasing. A workplace in the general public is alluded to as an "Association" and when we notice the expression "Equity" we are alluding to the value allocated in that workspace. In 1971, a logician named John Rawls referenced that value is the equivalent word of "Equity" and
Robinson (2004) referred to from this scholar later. He additionally pinpointed that in any organization or International Journal of Business and Management Vol. 13, No. 9; 201869 organization the absolute first significant thing that should be completed is equity and reasonableness towards its representatives. Moreover, John depicted insights about the judicious acknowledgment of value standards and directions. At the point when it came to Justice, there were two noteworthy guidelines that John consistently acted by those. The primary standard referenced that it was the privilege of everybody to appreciate fundamental social equality and opportunities and the subsequent guideline referenced that, everybody should have the corresponding rights and choices in the general public. It was referenced by John that on those occasions, there were out of line issuance of assets because solitary those individuals who had abilities and interests got the opportunity to exceed expectations. Afterward, Cohen and Greenberg (referred to in Robinson 2004) were among the principal specialists who found a relationship between the field brain research and the philosophical writing with respect to Justice.

\subsection{Turnover Intention}

If we allude to Tett and Meyer (1993) we can comprehend that they depicted Turnover Intention as the purposeful and preparation of the workforce to desert their establishment. In fact, this is the last in the movement of Withdrawal Cognition, which incorporates, thinking about leaving and applies to search for a substitution work. Even though TIs don't generally cause a real turnover, anyway Bluedorn (1982) found that Turnover Intentions had a high connection with real turnover in the previous 13 or 14 information gathered inquiries about. As a matter of fact, inquiries about did dependent on Turnover Intentions, which show that Turnover Intentions is the most ordinary factor for elective turnover (Lambert, Hogan, and Barton, 2001).

\subsection{Organizational Justice and Employer Turnover Intention}

Allude to Moorman (1991), when working staff have begun to comprehend their establishment, they begin to show positive conduct and great working assurance towards their given assignments, results, and their bosses. Most analysts have a great similarity on Turnover Intention (Hellman, 1997); therefore, Turnover Intention regularly alludes to a representative's will to leave an organization, or the evacuation of a worker by a predominant to benefit the organization. Inquiries about dependent on information assortment show that Turnover Intentions the most compelling variables that anticipate the real Turnover frame of mind (Griffeth, Hom, and Geatner, 2000; Hemdi, 2006). There is really a significant connection amongst TI and the genuine Turnover (Lambert, Hogan and Barton, 2001).

\subsection{Job Satisfaction}

The possibility of motivation in relation to work satisfaction is indicated in past examinations, as per Hamlett (2014), work satisfaction is made by "Helpers" factor. Same with the Value Theory of occupation satisfaction (Greenberg 2010), "Helpers" is an uncertain word utilized in the work satisfaction set. It can incorporate various positive outcomes or elements that a laborer esteems, for instance, individual or gathering achievements, beneficial steady work, accepting 
prizes, affirmation or certification from others, included obligation, calling advancement, singular improvement, etc.

\subsection{Organization Justice and Job Satisfaction}

The idea of "Worker First, Customer Second" (EFCS) is begotten by the American CEO of HCL Technologies, Vineet Nayar (2010) who steers one of the biggest I.T. redistributing firms on the planet. His thought is to esteem and approach workers with deference and full help, at that point this regard and cooperative attitude would go to the client, in the end, advantage the organization. While in Malaysia, regarding British Broadcasting Corporation (BBC) (2010), Group CEO of Air Asia, Malaysian home-developed minimal effort air Flight Company, Tony Fernandez additionally adjusted a similar way of thinking in dealing with the 8000 work powers of Air Asia (starting at 2010).

\subsection{Distributive, Interactional, and Procedural Justice}

There appears to interrelations between the three classes of decency presented in the past section; be that as it may, the aggregate examinations of the information from a few separate investigations on the issue show one of a kind gradual change clarifying the precise distinction among them(Cohen and Spector, 2001; Colquitt, et al, 2001; Hauenstein, 2001). In view of the definition, interactional reasonableness is how well the workers are dealt with when game-plans are occurring, (Bies and Moag, 1986). There are four attributes to show the particular line between this kind of reasonableness and the others: regard for example how chivalrous the administration acts towards the representatives; honesty, if the business conceals any fact from the workers; support, arrangement of data and explanation on the present game-plans in the association; and legitimacy, how fair-minded the business is, (Greenberg, 1993; Moorman, 1991).

\section{III.METHODOLOGY}

\subsection{Research Framework}

The study structure introduced underneath contains three key factors. They incorporate Organizational Justice and Turnover Intention (representative variable). Organizational Justice which is the main component that the present investigation is aimed to examine in the private organization has divided into three dimensions. These factors will be explored with an end goal to set up their effect on the dependent variable. The study received an exploration structure suggested by (Niehoff and Moorman, 1993), which measure Organizational Justice from three different dimensions (Distributive Justice, Interpersonal Justice, Procedural Justice).

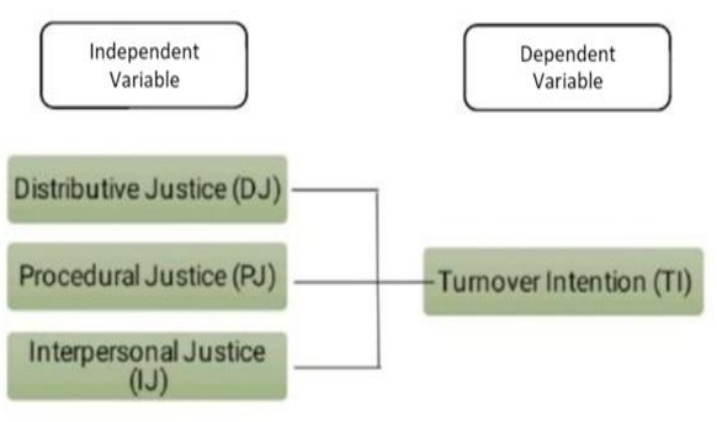

Figure 1: Conceptual Framework of turnover intention and organizational justice

\subsection{Hypotheses of the research}

The following are the Hypotheses which would be utilized to the exploration questions composed in the past section, so the following few theories can be found which are recorded underneath to examine the connection among the independent variables and the dependent variable.

H1: There is a positive relationship among employee's TI and DJ.

H2: There is a positive relationship among employee's TI and PJ.

H3: There is a positive relationship among employee's TI and IJ.

\subsection{Population and Sampling Design \\ 3.3.1 Target Population}

Kuwaitis non-administrative staff laborers in private segments in Kuwait, paying little respect to their sexual direction, age, ethnicity and proportion of month to month pay who can identify with by electronic mail or in very close have been picked as the possible respondents to the investigation. Two sorts of audits were dispersed among the respondents which were on the web and printed reviews. A large portion of the Kuwaitis associations' working staffs who came into correspondence when the data aggregation (either by email or eye to eye) was going on, responded to the overviews on a deliberate reason due to the possibility of Convenience Sampling Method. The rundown was gained from the Directorate General of Human Resource Development of associations which fills in as best source with respect to business data. The rundown joins all the agents in the private segment including the supervisors.

\subsubsection{Sampling Size}

A sample is a subset of masses (Zikmund, W., Babin, B., 2016). Since it isn't reasonable to get each one's data from these people, along these lines it is fundamental to pick the model gauge (Zikmund, W., Babin, B., 2016). Kuwaitis staff workers in private associations populace size are formed from 500 staffs and a survey of 273 will be dispersed considering $80 \%$-gauge reaction rate and 5\% Marginal error to ask $95 \%$ confidence level. Thus, to keep up a key good way from the issue of response inclination and to manufacture the response rate for this examination, the specialist decides to use a case of 273 for instance gauge for this investigation. 


$$
n=\frac{c N}{1+c N * e^{2}}
$$

$\mathrm{n}=$ Required Sampling size (218)

$\mathrm{N}=$ Population Size $(500)$

$\mathrm{e}=$ Acceptable Error (0.05)

$\mathrm{c}=$ Confidence Level $(0.95)$

Sampling Size $=\frac{n}{R R}$

RR=Response Rate (0.8)

Sampling Size $=273$

\subsubsection{Sampling Techniques}

In this examination, a fundamental unpredictable testing framework was utilized to pick 273 laborers from the Directorate General of Human Resource Development. This is by virtue of it gives the creator the adaptability to consolidate all segments in the people (Cochran, 2007; Fuller, 2009). The overview and the names of the laborers were procured from the secretary of the pioneer of the main's office. This rundown contains the number of agents in each office and their movement tittle. From that point on, the researcher put all the names into consideration and steadily including in the process picking every part out of the far-reaching masses until the point that the expert achieves the necessary number of test measure that was sensible for this study.

\subsection{Instrument of Study}

To collect basic examination for this examination, an investigation would be dropped to agents who work in Kuwait tertiary preparing associations. Remembering the ultimate objective to show the instrument, the variable proportion of OJ was assessed using a seventeen-things scale made by (Niehoff and Moorman, 1993). The Justice scale has three estimation estimations of understanding interpersonal Justice with nine inquiries, distributive Justice with five inquiries, and procedural Justice with six inquiries. Turnover Intention, which is the fundamental regard, was assessed with a four inquiries scale balanced from (Griffeth, Hom, and Gaertner, 2000).

\subsection{Research Design}

Research configuration offers creators the bearing of investigation and execution, by giving crucial information on the examination question (Hair et al., 2014). An examination by Salkind et al., (2010) portrayed investigate layout as the framework and structures of an investigation picked by an investigator with an ultimate objective to achieve the standard required in doing data get-together and examination. The master orders explore approach into one, for instance, quantitative research (Salkind et al., 2010).

In this examination, the researcher grasped a quantitative methodology with an ultimate objective to test the association between the investigation factors (Kreuger and Neuman, 2006).

As in this examination, the genuine point is to take a gander at the association between tip-top work structure, progressive culture and the execution of agents in the Kuwait private area. Basically, quantitative methodology similarly enables an expert to analyze a colossal model that can without quite a bit of a stretch be summarize to the whole masses. Thusly, this examination uses individuals as its unit of examination (laborers in the Kuwait private area) and basic data will be accumulated by methods for the assignment of review. Again, this examination is a cross-sectional layout since data and allowing for the collection of data in a brief timeframe.

\section{RESUlt AND Discussion}

\subsection{Response Rate}

In this investigation information was gathered from workers in the position of supervisors, other employees and directors in the Human Resource Management Development of the private organizations in Kuwait. In an effort to increase the response rate, telephone calls and send message short (SMS) were put across to those employees who the enumerator or the secretary could not be able to collect their answer (Sekaran, 2003) prior departing Kuwait to the Limkokwing University of Creative Technology, Malaysia for academic resumption. Kuwaitis staff employees in private organizations population size is composed of 500 staffs and a questionnaire of 273 shall be distributed considering $80 \%$ estimate response rate and 5\% Marginal error to urge a 95\% confidence interval. Therefore, the required sample size for this study is 218 .

One method for surveys was disseminated between the representatives (printed polls). As indicated by this endeavor 235 polls were recovered out of 273 studies circulated. This makes a reaction pace of $86(\%)$. Giving the proposal by Sekaran (2003); Hair, Black Babin and Anderson (2010) a reaction pace of $30 \%$ or more is palatable for a study.

Table 4.1 below demonstrates the complete number of overviews disseminated, gathered from the workers and the number of studies that had been secured by the respondents.

Table 4.1: Response Rate

\begin{tabular}{|l|l|l|}
\hline & Number & \% \\
\hline Distribute & 273 & $100 \%$ \\
\hline Responded & 235 & $86 \%$ \\
\hline Completed & 229 & $83.9 \%$ \\
\hline
\end{tabular}

From table 4.1 , this study recorded a reaction rate of $86 \%$. Hence, a reaction rate of $86(\%)$ recorded in this investigation is accepted to be an incredible accomplishment. Again, out of the 235 questionnaires that were returned 6 surveys i.e. $(2.5 \%)$ were unusable because they were not totally filled therefore, they were erased (Bell and Bryman, 2007).

\subsection{Descriptive Analysis}

Writing has fought that reasonable examination is coordinated after data screening and cleaning. Fittingly, Pallant (2007) recognized that reasonable examination explains the characteristics of the respondents who have 
drawn in with an investigation. It describes the characteristics of the model despite watching out for some exploration issues. They incorporate sexual direction, age, task, higher educational ability, working information. The data is shown in Table 4.2.

Table 4.2: Demographics of Respondents

\begin{tabular}{|c|c|c|c|}
\hline Category & Items & $\begin{array}{l}\text { No. } \\
\text { Respondents }\end{array}$ & $\%$ \\
\hline \multirow[t]{2}{*}{ Gender } & Male & 219 & $93.2 \%$ \\
\hline & Female & 16 & $6.8 \%$ \\
\hline \multirow{2}{*}{$\begin{array}{l}\text { Marital } \\
\text { Status }\end{array}$} & Married & 169 & $72 \%$ \\
\hline & Single & 66 & $28 \%$ \\
\hline \multirow[t]{5}{*}{ Age } & $18-20$ & 3 & $1.2 \%$ \\
\hline & $21-30$ & 51 & $21.6 \%$ \\
\hline & $31-40$ & 63 & $26.5 \%$ \\
\hline & $41-50$ & 89 & $38.2 \%$ \\
\hline & $51+$ & 29 & $12.5 \%$ \\
\hline \multirow[t]{4}{*}{ Designation } & Director & 34 & $14.2 \%$ \\
\hline & $\begin{array}{l}\text { Deputy } \\
\text { Director }\end{array}$ & 17 & $7.4 \%$ \\
\hline & $\begin{array}{l}\text { Head } \\
\text { Section }\end{array}$ & 26 & $\%$ \\
\hline & Others & 158 & $67.3 \%$ \\
\hline \multirow[t]{6}{*}{ Ethnicity } & Kuwait & 47 & $20 \%$ \\
\hline & Egypt & 82 & $35 \%$ \\
\hline & Syria & 26 & $11 \%$ \\
\hline & Palestine & 15 & $6.2 \%$ \\
\hline & India & 28 & $12 \%$ \\
\hline & Others & 37 & $15.8 \%$ \\
\hline
\end{tabular}

\begin{tabular}{|c|c|c|c|}
\hline Category & Items & $\begin{array}{l}\text { No. } \\
\text { Respondents }\end{array}$ & $\%$ \\
\hline \multirow[t]{5}{*}{ Income } & $100-250 \mathrm{KD}$ & 40 & $17.2 \%$ \\
\hline & $251-400 \mathrm{KD}$ & 75 & $32 \%$ \\
\hline & 401-600KD & 54 & $23 \%$ \\
\hline & 601-800KD & 43 & $18 \%$ \\
\hline & $801 \mathrm{KD}+$ & 23 & $9.8 \%$ \\
\hline \multirow{4}{*}{$\begin{array}{l}\text { Educational } \\
\text { Qualificatio } \\
\text { n }\end{array}$} & Doctorate & 17 & $7.2 \%$ \\
\hline & Master & 63 & $26.7 \%$ \\
\hline & Bachelor & 97 & $41.35 \%$ \\
\hline & Diploma & 58 & $24.7 \%$ \\
\hline \multirow{4}{*}{$\begin{array}{l}\text { Work } \\
\text { Experience }\end{array}$} & $<1$ year & 25 & $10.5 \%$ \\
\hline & $1-5$ years & 61 & $25.9 \%$ \\
\hline & 6-10 years & 87 & $37.1 \%$ \\
\hline & $11+$ years & 62 & $26.5 \%$ \\
\hline \multirow[t]{3}{*}{ Department } & $\begin{array}{l}\text { Director } \\
\text { Office }\end{array}$ & 26 & $11.10 \%$ \\
\hline & $\begin{array}{l}\text { Finance and } \\
\text { Accounting }\end{array}$ & 32 & $13.60 \%$ \\
\hline & Marketing & 52 & $22.23 \%$ \\
\hline
\end{tabular}

\begin{tabular}{|l|l|l|l|}
\cline { 2 - 4 } & Advertising & $\mathbf{7 7}$ & $\mathbf{3 2 . 7 \%}$ \\
\cline { 2 - 4 } & Supervisor & 29 & $12.35 \%$ \\
\cline { 2 - 4 } & $\begin{array}{l}\text { Human } \\
\text { Resource }\end{array}$ & 19 & $8.1 \%$ \\
\hline Total & & 235 & $100 \%$ \\
\hline
\end{tabular}

Table 4.2 is the statistic information of respondents that took an interest in this review from the Directorate of Human Resource Development of the private organizations in Kuwait. With profound regard to the sex of the respondent, it is apparent from the above (Table 4.2) that the greater part of the respondents in the service is Male (93.2\%), while remaining $(6.8 \%)$ respondents illustrate the female gathering of the aggregate reaction. These outcomes bolster the thought that male representatives constitute a larger part in almost everybody in Private organizations. The reaction illustrates representatives that were classify into five diverse age review $18-20$ (1.2\%), 21-30 (21.6\%), 31-40 (26.5\%), 41-50 (38.2\%) and 51 and over $(12.5 \%)$. Even though there exist provisional laborers in Kuwait association administration which are not considered as individuals from the affiliation. Regarding the task of those that investigate the diagram from this industry. An aggregate number of 34 (14.2\%), 17 (7.4) directors, deputy directors, and Head Section respectively the total of $32.7 \%$ top managers took an interest in the overview. It is extremely uncommon for executives in this organization to be completely engaged with a study as the author had witnessed in the past review in view of their bustling nature. Their craving to be engaged with the study additionally demonstrates the significance of this study to the organization. Just 26 (11.10) about the head Section constitute the respondents for this study. Besides, $67.3 \%$ of the workers in this investigation are inside the rank of different positions as at the season of gathering information for the study, this illuminates the researcher that the example is a genuine delegate.

The table above likewise demonstrates that the dominant part of respondents (34\%) in the Kuwait private organization holds a master's degree or higher (doctorate certificate $7.2 \%$, master's degree $26.7 \%$ ). The reason could be rapscallion by the present need by individuals to redesign their insight regardless of the position held in the association. Additionally, in this study, bachelor certificate $41.35 \%$ this might be affected by the presumption that qualification certification is progressively swinging to be the base capability for any association whether public or private. While just $24.7 \%$ of workers that took part in this review had a recognition diploma at the time of this study. As far as representatives work involvement in the Kuwait private section organizations that share in this investigation.

The researcher found that $63.6 \%$ have more than 6 years' experience of working in the service. The above outcome legitimizes that most representatives that took an interest in the overview tend to be knowledgeable about the service consequently, they are accepted to have significant information about the human resource in the association. This is taken after by representatives with less than 6 years $(25.9 \%)$. Just $10.5 \%$ of the representatives that have less than one year took part in this investigation. 
Concerning the division that representatives that take part in this study, the Main respondent were the majority from the Advertisement department $(32.7 \%)$. While $22.23 \%$ are from the Marketing department. Another $11.10 \%$ was a delegate from the chief's office. While $13.6 \%, 12.35 \%, 8.1 \%$ are illustrating from, Finance and Accounting, Supervisor and Administrator and Human Resource respectively. The above insights legitimize that most all the divisions in the service were completely covered.

\subsection{Data Screening and Cleaning}

Following data entering in the SPSS variation 20.0, the expert as such lead screening and cleaning, which incorporate checking if there is goof during the time spent social affair data in this examination. This is relentless with composing that it is outstandingly crucial for a scientist to affirm and re-check if there is any slip-up in the data assembled (Pallant, 2007).The researcher submitted this proposition since blunder may occur during the time spent entering the data into the structure and this possibly alters the data while looking at the data. Screening the data would help the researcher with getting aware of a part of the data that are out of range in this way, making the essential change before driving the genuine examination considering the way that out of range data may impact the eventual outcomes of some examination, for instance, relationship (Pallant, 2007). In any case, checking the delayed consequence of the yield of the beginning period of the examination an aggregate of two out of range data were recorded. This thusly prepares for the researcher to advance to the accompanying stage in the data study.

\subsubsection{Treatment of Outliers}

Writing has recommended that special cases are sensitive to various backslides whether low or high scores (Pallant, 2007). This thusly requires the necessity for this examination to check if there are any inconsistencies to keep up a vital good way from the difficulty it may possibly make over the range of running the backslide study. Among the best approach to coordinate this is through a histogram diagram despite standard remaining plot. The present examination recognized special cases by methods for the histogram and Mahala Nobis. A total of two cases were eradicated from the rule data out of 235 respondents got. A brief timeframe later, the histogram and boxplot were plotted again to check whether there are any occurrences of special cases. In like way, checking the histogram and boxplot it reveals that there were no exceptions.

\subsubsection{Normality Test}

The essential thought of commonness is to check if the data score is consistently circled. It shapes one of the key doubts during the time spent running backslide study in an examination of this nature (Pallant, 2007). Along these lines, is a bit of the data screening going before examinations, for instance, relationship, factor study, backslide examination and others can be used. The examiner uses run of the mill Q-Q plot in choosing whether there is any occasion of Normality of data. This is unsurprising with the composing that data trails the run of the mill transport on a standard probability plot will end up clear in a straight line (Coakes and Steed, 2003). In the light of the over, the conventionality test for all the estimations in Organizational Justice plotted and examined about in the going with subheadings.

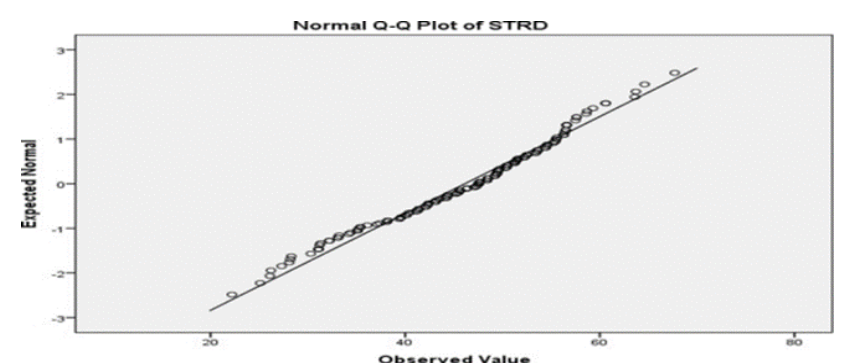

Figure 4.1: The Normality of items in Distributive Justice

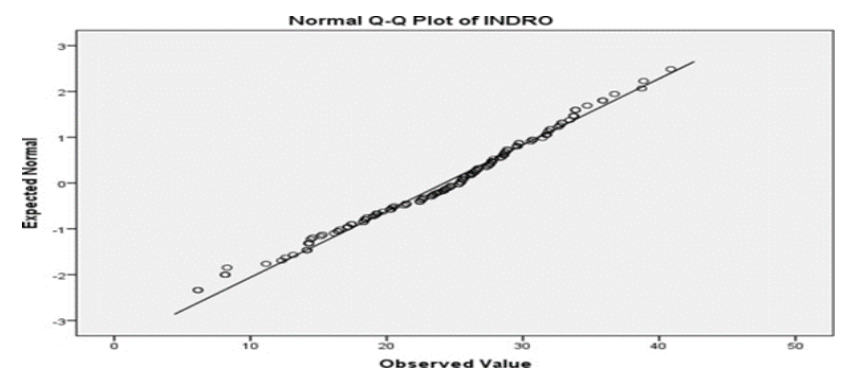

Figure 4.2: The Normality of items in Interpersonal Justice

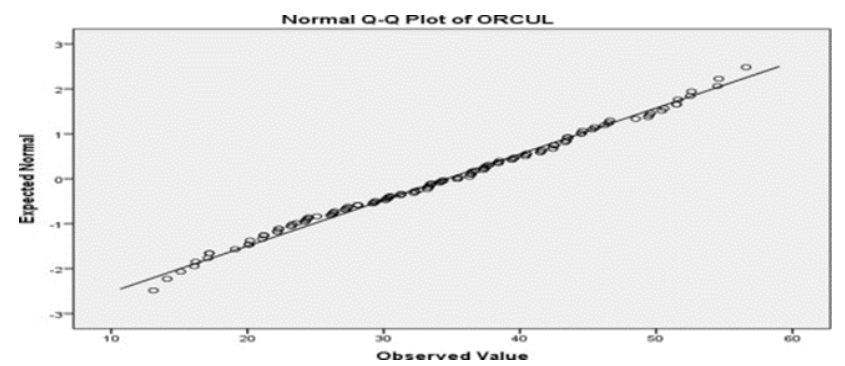

Figure 4.3: The Normality of items in Procedural Justice

In spite of the way that not extremely less of the things strayed from the line, the delayed consequence of the typicality test exhibits that the data are well scattered, considering the way that a huge segment of the scores appeared in the midst of the diagram as can be found in the abovementioned (outline 1-4). The qualification from the cuts may possibly cause by the respondent's reaction to the things in the overview. Considering uniqueness in the respondent's response to a comparative request possibly changes the characterization of data not to be in solid strata. This examination proposed that there is an association between authoritative Justice three measurements. As such suggests they are authentic and worthy to be used. The discussions show the Normality test base on the factors while the result displayed in the table was directed to the total things in Organizational Justice. This is a direct result of the way that a relationship can be made between the graphical and numerical data.

\subsection{Reliability Analysis Before Factor Analysis}

In the light of coordinating the pilot testing for this examination, this investigation in like manner drove an 
enduring quality test for the entire form before a factor study was driven. The immovable nature of any examination is best assessed by Cronbach's alpha estimation. It is considered the extent of the inside consistency of an investigation instrument (Zikmund, 2003). Immovable quality gauges how much results are unsurprising with time, also, goes about as the best depiction of the number of occupants in an examination (Golafshani, 2003). Driving immovable quality will help the examiner with assessing the information accumulated from the greater model (Sekaran, 2003). The enduring quality examination was performed using a factual bundle for sociology (SPSS) programming. High constancy results show that the instrument has an irrelevant mistake inconsistency. However, for things to end up critical in the genuine investigation, it is major for the stacking of such thing to have a more noteworthy create on what they hope to scale than different develops. The result of the enduring quality examination before the factor study is shown in table 4.3.

Table 4.3: Reliability Test

\begin{tabular}{|l|c|c|}
\hline Variables & No of Items & $\begin{array}{l}\text { Cronbach } \\
\text { Alpha }\end{array}$ \\
\hline $\begin{array}{l}\text { Procedural } \\
\text { Justice }\end{array}$ & 5 & 0.706 \\
\hline $\begin{array}{l}\text { Interpersonal } \\
\text { Justice }\end{array}$ & 7 & 0.703 \\
\hline $\begin{array}{l}\text { Distributive } \\
\text { Justice }\end{array}$ & 5 & 0.742 \\
\hline $\begin{array}{l}\text { Turnover } \\
\text { Intention }\end{array}$ & 4 & 0.801 \\
\hline
\end{tabular}

From the outcome of table 4.3 over, the Cronbach's Alpha before the factor examination for all the segments in Organizational Justice (Interpersonal Justice, Distributive Justice, and Procedural Justice) autonomous factors are more unmistakable than 0.7. researchers have endorsed that in evaluating the reliability of an examination, a Cronbach Alpha regardless of 0.6 are set apart as poor, while 0.7 or more are incredible and enough. This exhibited this examination can keep on testing the genuine model. The accompanying section incorporates the figure investigation of things this examination to know the things that have a spot with each part before driving the steady quality.

\subsection{Hypotheses Testing}

In this examination, the correlation examination was coordinated through linear regressions. Particularly, the Pearson association examination was grasped explicitly to offer more perception of the nature of the connection between Turnover Intention, and Organizational Justice. Also, numerous relapse examination was utilized to develop the immediate association among the Responsive variable and the. Explanatory variable

\subsection{Correlation Analysis Test}

The relationship study was finished remembering the ultimate objective to examine and realize how related these things are. Composing has fought that the estimation of association is to help the researcher in working up issues of multidisciplinary (Mayer et al., 2006).

Pondering issues of multidisciplinary, Cooper and Schindler (2003) bore witness to that no correct standard in working up the degree of relationship be tween's components that have multidisciplinary cases. They fought that a relationship that is 0.80 or more may be dangerous consequences, a lower association is satisfactory.

The aftereffect of the connection investigation represents in table 4.4 uncovered that Distribution Justice has an estimation of 0.23 with a significant level of 0.000 . This exhibited, there is a low connection be tween's Distributive Justice and representatives Turnover Intention. Once more, the aftereffect of the connection investigation indicated that Procedural Justice has a relationship coefficient of 0.594 at 0.000 significant level. This recommends, there is a positive connection between Procedural Justice and representatives Turnover Intention. In addition, it is proof in the connection examination bring about Table 4.8 that Interpersonal Justice has a significant correlation with workers Turnover Intention at an estimation of 0.689 with 0.000 significant levels. This indicated, there is a huge constructive connection between Interpersonal Justice and workers Turnover Intention. Table 4.4 shows the examination outline of the connection between Organizational Justice measurements and workers Turnover Intention.

Table 4.4: Correlation result of Organizational Justice dimension to employees Turnover Intention

\begin{tabular}{|l|c|c|}
\hline $\begin{array}{l}\text { Independent } \\
\text { variable }\end{array}$ & $\begin{array}{l}\text { Dependent } \\
\text { variables }\end{array}$ & Significant level \\
\hline Distribution Justice & $0.23 * *$ & 0.000 \\
\hline Procedural Justice & $0.594 * *$ & 0.000 \\
\hline $\begin{array}{l}\text { Interpersonal } \\
\text { Justice }\end{array}$ & $0.689 * *$ & 0.000 \\
\hline \multicolumn{2}{|l}{$* 0<\mathrm{P}<0.05$} &
\end{tabular}

Due to Cooper and Schindler (2003), this investigation inferred that there is a connection between employees' Turnover Intention and Organizational Justice dimensions. As per Zikmund (2003), the connection doesn't include circumstances and logical results regardless of how agreeable critical it is. Consequently, this investigation gives the premise to promote examination.

\subsection{Regression Analysis}

The numerous regression study was directed to choose the variable or measurement that has more grounded or flimsier associations with representatives Turnover Intention. The regression analysis study in Table 4.5 shows that $59.7 \%$ ( $\mathrm{R}$ square $=0.597$ ) of the fluctuation of Turnover Intention has been fundamentally explained by Organizational Justice. This is a direct result of the high estimation of beta they encase in explaining Turnover Intention. Relational Justice seems to have the most critical pledge to the Turnover Intention of laborers in the Private Organizations with a beta estimation of $(\beta=0.371)$, trailed by Procedural Justice $(\beta=0.326)$, and Distributive Justice contributing insignificant motivation to workers Turnover Intention $(B=0.029)$. The result is showed 
up in Table 4.5.

Table 4.5: Regression Analysis

\begin{tabular}{|l|l|l|}
\hline Variables & Beta (B) & Sig \\
\hline Distributive Justice & 0.029 & 0.627 \\
\hline Interpersonal Justice & 0.371 & $0.001 * *$ \\
\hline Procedural Justice & 0.326 & $0.000 * *$ \\
\hline \multicolumn{2}{|l|}{$=0.597 \mathrm{~F}=53.457$} & \\
\hline
\end{tabular}

Table 4.5 above shows the different regression investigation of Organizational Justice dimensions. Remembering the ultimate objective to confirm the model shown in this examination, by methods for testing the major hypothesis, a different numerous relapse investigation results were shown at the centrality level of $p<0.05$. The primary task before the researcher is to avow the hypotheses as regards to the association between Organizational Justice measurements and Turnover Intention. The accompanying subsection exhibits the theory choice from the result of regression.

\subsection{Hypotheses Decision}

\section{Table 4.6: Hypotheses Decision}

\begin{tabular}{|l|l|l|}
\hline H1 & $\begin{array}{l}\text { There is a significant positive } \\
\text { relationship between Distributive } \\
\text { Justice and employees Turnover } \\
\text { Intention. }\end{array}$ & Rejected \\
\hline $\mathbf{H 2}$ & $\begin{array}{l}\text { There is a positive relationship } \\
\text { between Interpersonal Justice and } \\
\text { employees Turnover Intention. }\end{array}$ & Accepted \\
\hline $\mathbf{H 3}$ & $\begin{array}{l}\text { There is a positive relationship } \\
\text { between Procedural Justice and } \\
\text { Turnover Intention. }\end{array}$ & Accepted \\
\hline
\end{tabular}

\section{RESEARCH IMPLICATIONS AND RECOMMENDATION}

\subsection{Implications of The Study}

The disclosures of the examination have hypothetical and authoritative consequences, that are discussed in the going with portion.

\subsubsection{Theoretical Implications}

The discoveries of this investigation have striking hypothetical ramifications. to begin with, this investigation added new data to the assortment of information in elite organizational justice and turnover intention representative's execution literary works.

By furthermore revealing the association among hierarchical equity and turnover goal with respect to under-researched private affiliation. Since a predominant piece of the examination on hierarchical equity and delegates variables were coordinated inside the setting of made and sweeping advantage arranged affiliations their revelations may not be summarized in another setting particularly inside the Persian inlet region, for instance, Kuwait because of the uniqueness of nature. as such, this investigation has vanquished any obstacle especially with respect to Kuwait's private segment.

Besides that, this examination supports probability speculation and RBV in different manners. The ultimate objective that the disclosures of the investigation certified that not all equity can be material in every one of a kind condition. This Signify private segment associations, particularly in the making economy, required a greater chance to get tied up with the standard Organizational Justice rehearses. This is a great implication for future experts to be careful about in perceiving the components that will improve laborers' execution. This is consistent with resource base view speculation (RBV) asserting that not all preparation is vital drivers of legitimate execution (Barney, 2001). Again, this examination in like manner certifies the plausibility speculation which fought that the human resource practices of affiliation are at risk to different essential conditions that act in better execution (Gomez-Mejia et al., 1992). It is appropriately suggested in the propose inquire about that investigators should empower nature to choose the style to be grasped during the time spent coordinating their examination. This is because different settings give unmistakable revelations made by researchers, especially on Distributive Justice.

\subsubsection{Managerial Implications}

For the most part, this exploration has revealed that Distributive Justice has not so much been impacted inside the setting of the private segment. Thusly, this examination fills in as an eye-opener for overseers in this condition. Thusly, the eventual outcome of this examination fills in as a clarion call for chiefs in the Kuwait private associations towards the difference in Distributive Justice that can be a wellspring of huge worth creation for the affiliation despite when they face inconvenience in realizing Distributive Justice. It has furthermore been developed in this examination that a blend of Organizational Justice is related to Turnover Intention. Given the investigation reinforce, there must make care, clashing to conventional human asset rehearses, Particularly, as a rule, society advantage territory who rely upon standard human resource practices in anticipating high results. The result from this examination in like manner recommended that redesigning agents execution in the affiliation anticipate that boss should improve their lifestyle additional time to facilitate with the affiliations dynamic condition, with the understanding that particular social practices, for instance, giving extraordinary organization, respect in social correspondences with subordinates and phenomenal practices in settling battle among laborers can discuss the cohesiveness of people.

Furthermore, for those in private associations and organizations that related with the headway value programs, for instance, approach producers, may use these disclosures for the improvement of their planning preparing projects or module to such a degree, that before giving setting they up should get some answers concerning the readiness needs, consider laborer's needs, grasp their characteristics and 
weaknesses. Again, it is proposed in this examination that those in the endeavors of overseeing privately owned businesses ought to explain their arrangements, prepared for how goals should be practiced and how systems of capacity should be evaluated.

\section{LIMITATIONS AND RECOMMENDATION}

The present investigation isn't without hindrances. The data assembled were cross-sectional and causality can't be inferred. The examination data was furthermore considering self-reports which may be exposed to social drawing in quality tendency. On the other hand, an affirmation of a puzzle can decrease such tendency despite when responses are related to tricky topics. Future works should henceforth join target extents of execution. This examination explores only three estimations of Organizational Justice, for example, Interpersonal Justice, Procedural Justice, and Distributive Justice to explain Turnover Intention in the model.

There may be various increasingly various estimations of Organizational Justice that could affect these associations. The future examination needs to explain these estimations to endorse the authoritative Justice agent's execution relationship. As needs are, future research should submit closer thought by melding an increasingly broad estimation of the value in associations.

Even though the result showed a negative help between employee turnover intention and Distributive Justice, it ought not to be yielding red that Distributive Justice has no suitability on a responsive variable of this investigation. Truth be told, respondents are laborers of private associations with unmatched characteristics. While surveying the Distributive Justice of private parts obviously would create the extensive differing result. As such, the creator recommends extra investigate is required to find the nearness association among Distributive Justice and representative's turnover goal in advantage arranged affiliations or utilize other evaluation techniques.

Moreover, the revelations of this examination may not be significant to various affiliations or industry because of the little model size. Along these lines, it is recommended that future examinations should enlarge the degree of extension inclusion past the private associations to various administrations and zones with the discoveries will be progressively broad that revelations will be more extensive in Kuwait and maybe other Persian Gulf nations.

\section{CONCLUSION}

This examination was driven in the Kuwait firms which are the private advantage section. Along these lines, the result of the examination is vital and pertinent to general society territory or various affiliations that have comparable characteristics. Again, this examination addresses one of the underlying advances toward understanding the association between Organizational Justice, and Turnover Intention with respect to the private area of Kuwait. Along these lines, the examination is stand-out with the ultimate objective that it has backed to dispatch the gap to grasp the piece of Organizational Justice and responsive variable in the all-inclusive community division. This examination gives affirm that Organizational Justice dimensions are identified with Turnover Intention.

Note that today affiliations must surpass desires to meet accomplices wants, along these lines, the scope of affiliations information on Organizational Justice and the capacity to improve an unrivaled culture, is basic to the continuance of the associations. Subsequently, the proposed research endorsed that associations should get a value system to achieve a world-class staff, rather than the standard procedures for execution appraisal. This is because Turnover Intention will help the administration with tending to execution inadequate and give appropriate and input that will bolster the agent's employment headway. It will in like manner give an increasingly one of a kind structures that will express the genuine degree of Interpersonal Justice that will relate with nature thought of the businesses in the associations.

The sociology phrasing "Organizational Justice" was first instituted by Greenberg in 1990 (Hamlett 2014; Zhang 2006). Every one of the words utilized in the term has their different implications which will make it simpler for individuals or workers to comprehend the phrasing. A workplace in the general public is alluded to as an "Association" and when we notice the expression "Equity" we are alluding to the value relegated in that workspace. In 1971, a scholar named John Rawls referenced that value is the equivalent word of "Equity" and Robinson (2004) referred to from this rationalist later. He additionally pinpointed that in any foundation or organization the absolute first significant thing that should be completed is equity and decency towards its workers. What's more, John depicted insights about the judicious acknowledgment of value standards and guidelines. At the point when it came to Justice, there were two significant guidelines that John consistently made a move as per those. The main principle referenced that it was the privilege of everybody to appreciate essential social liberties and opportunities and the subsequent standard referenced that, everybody should have the corresponding rights and choices in the general public. It was referenced by John that on those occasions, there was unreasonable issuance of assets in light of the fact that lone those individuals who had abilities and interests got the opportunity to exceed expectations. Afterward, Cohen and Greenberg (referred to in Robinson 2004) were among the main analysts who found a relationship between the field brain research and the philosophical writing with respect to Justice.

\section{REFERENCES}

1. Akgunduz, Y. and Bardakoglu, O., 2017. The impacts of perceived organizational prestige and organization identification on turnover intention: The mediating effect of psychological empowerment. Current Issues in Tourism, 20(14), pp.1510-1526.

2. Brien, A., Thomas, N. and Hussein, A.S., 2015. Turnover intention and commitment as part of organizational social capital in the hotel industry. Journal of Human Resources in Hospitality \& Tourism, 14(4), pp.357-381. 
3. Bell, E. and Bryman, A., 2007. The ethics of management research: an exploratory content analysis. British journal of management, 18(1), pp.63-77.

4. Bartlett, J. E., Kotrlik, J. W. and Higgins, C. C. (2001) 'Organizational research: Determining the appropriate sample size in survey research', Information Technology, Learning, and Performance Journal. DOI: 10.1109/LPT.2009.2020494.

5. Coakes, S.J., Steed, L.G., Coakes, S.J. and Steed, L.G., 2003. Multiple response and multiple dichotomy analysis. SPSS: analysis without anguish: Version 11.0 for Windows, pp.215-224.

6. Chen, I.H., Brown, R., Bowers, B.J. and Chang, W.Y., 2015. Work- to- family conflict as a mediator of the relationship between job satisfaction and turnover intention. Journal of advanced nursing, 71(10), pp.2350-2363.

7. Greenberg, J., 1990. Employee theft as a reaction to underpayment inequity: The hidden cost of pay cuts. Journal of applied psychology, 75(5), p.561.

8. Griffeth, R.W., Hom, P.W. and Gaertner, S., 2000. A meta-analysis of antecedents and correlates of employee turnover: Update, moderator tests, and research implications for the next millennium. Journal of management, 26(3), pp.463-488.

9. Golafshani, N., 2003. Understanding reliability and validity in qualitative research. The qualitative report, 8(4), pp.597-606.

10. McDonough, R.P. and Shakespeare, C.M., 2015. Fair value measurement capabilities, disclosure, and the perceived reliability of fair value estimates: A discussion of Bhat and Ryan (2015). Accounting, Organizations and Society, 46, pp.96-99.

11. Newman, A., Miao, Q., Hofman, P.S. and Zhu, C.J., 2016. The impact of socially responsible human resource management on employees' organizational citizenship behaviour: the mediating role of organizational identification. The international journal of human resource management, 27(4), pp.440-455.

12. Niehoff, B.P. and Moorman, R.H., 1993. Justice as a mediator of the relationship between methods of monitoring and organizational citizenship behavior. Academy of Management journal, 36(3), pp.527-556.

13. Nik Nazli, N.N.N. and Sheikh Khairudin, S.M.H., 2018. The factors that influence transfer of training and its effect on organizational citizenship behaviour: evidence from Malaysia civil defence force. Journal of Workplace Learning, 30(2), pp.121-146.

14. Pallant, J.F. and Tennant, A., 2007. An introduction to the Rasch measurement model: an example using the Hospital Anxiety and Depression Scale (HADS). British Journal of Clinical Psychology, 46(1), pp.1-18.

15. Schneider, B., González-Romá, V., Ostroff, C. and West, M.A., 2017. Organizational climate and culture: Reflections on the history of the constructs in the Journal of Applied Psychology. Journal of Applied Psychology, 102(3), p.468.

16. Swalhi, A., Zgoulli, S. and Hofaidhllaoui, M., 2017. The influence of organizational justice on job performance: The mediating effect of affective commitment. Journal of Management Development, 36(4), pp.542-559.

17. Tam, W.W., 1999. An assessment of the relationships among organizational trust, organizational politics, and organizational justice, and their effects on merit pay outcomes in the Malaysian public sector.

18. Tamta, V. and Rao, M. K. (2017) 'The effect of organizational justice on knowledge sharing behavior in public sector banks in India: the mediating role of work engagement', International Journal of Business Excellence.

19. Teixeira, C., 2017. Transforming design matters.

20. Tekingündüz, S., Top, M., Tengilimoğlu, D. and Karabulut, E., 2017. Effect of organizational trust, job satisfaction, individual variables on the organizational commitment in healthcare services. Total Quality Management \& Business Excellence, 28(5-6), pp.522-541.

21. Wan, H.L., Sulaiman, M. and Omar, A., 2012. Procedural justice in promotion decisions of managerial staff in Malaysia. Asia Pacific business review, 18(1), pp.99-121.

22. Wang, H.J., Lu, C.Q. and Siu, O.L., 2015. Job insecurity and job performance: The moderating role of organizational justice and the mediating role of work engagement. Journal of Applied Psychology, 100(4), p.1249.

23. Whisenant, W., Lee, D.L. and Dees, W., 2015. Role congruity theory: Perceptions of fairness and sexism in sport management. Public Organization Review, 15(4), pp.475-485.

24. Wu, W.Y., Rivas, A.A. and Chen, Y.C., 2019. The role of team reflexivity as a mediator between project management skills, task familiarity, procedural justice, and product performance. Journal of Management \& Organization, 25(6), pp.876-895.
25. Xerri, M.J., 2014. Examining the relationship between organizational justice, job satisfaction and the innovative behavior of nursing employees. International Journal of Innovation Management, 18(01), p. 1450004.

26. Yamazakia, Y. and Petchdee, S., 2015. Turnover intention, organizational commitment, and specific job satisfaction among production employees in Thailand. Journal of Business and Management, 4(4), pp.22-38.

27. Zhan, X., 2015, May. The Impact Mechanism of Service Employees' Job Satisfaction on Service Quality: The Role of OCB and Turnover Intention. In 2015 International Conference on Service Science (ICSS) (pp. 79-82). IEEE.

28. Zhang, S. and Liu, Z., 2016. A meta-analysis of the relationship between organizational identification and turnover intention. Acta Psychological Sinica, 48(12), pp.1561-1573.

29. Zhang, Y., 2016. A review of employee turnover influence factor and countermeasure. Journal of Human Resource and Sustainability Studies, 4(02), p.85. 